\title{
Analysis of ice shelf flexure and its InSAR representation in the grounding zone of the southern McMurdo Ice Shelf
}

\author{
Wolfgang Rack ${ }^{1}$, Matt A. King ${ }^{2}$, Oliver J. Marsh ${ }^{1}$, Christian T. Wild ${ }^{1}$, and Dana Floricioiu ${ }^{3}$ \\ ${ }^{1}$ Gateway Antarctica, University of Canterbury, Private Bag 4800, Christchurch, New Zealand \\ ${ }^{2}$ School of Land and Food, University of Tasmania, Private Bag 76, 7001 Hobart, Australia \\ ${ }^{3}$ Earth Observation Center, German Aerospace Center (DLR) Oberpfaffenhofen, 82234 Wessling, Germany \\ Correspondence to: Wolfgang Rack (wolfgang.rack@canterbury.ac.nz)
}

Received: 8 February 2017 - Discussion started: 23 February 2017

Revised: 14 June 2017 - Accepted: 2 July 2017 - Published: 3 November 2017

\begin{abstract}
We examine tidal flexure in the grounding zone of the McMurdo Ice Shelf, Antarctica, using a combination of TerraSAR-X repeat-pass radar interferometry, a precise digital elevation model, and GPS ground validation data. Satellite and field data were acquired in tandem between October and December 2014. Our GPS data show a horizontal modulation of up to $60 \%$ of the vertical displacement amplitude at tidal periods within a few kilometres of the grounding line. We ascribe the observed oscillatory horizontal motion to varying bending stresses and account for it using a simple elastic beam model. The horizontal surface strain is removed from nine differential interferograms to obtain precise bending curves. They reveal a fixed (as opposed to tidally migrating) grounding-line position and eliminate the possibility of significant upstream bending at this location. The consequence of apparent vertical motion due to uncorrected horizontal strain in interferometric data is a systematic mislocation of the interferometric grounding line by up to the order of one ice thickness, or several hundred metres. While our field site was selected due to its simple boundary conditions and low background velocity, our findings are relevant to other grounding zones studied by satellite interferometry, particularly studies looking at tidally induced velocity changes or interpreting satellite-based flexure profiles.
\end{abstract}

\section{Introduction}

Ice shelves are the floating seaward extensions of the Antarctic Ice Sheet. They move vertically with ocean tides and are continuously bent in the grounding zone which forms their landward margin. Migration of this boundary indicates a change in ice dynamics and basal conditions and can be used to identify the onset of ice sheet instability (Schoof, 2007). Accurate mapping of the grounding zone at high temporal resolution is therefore vital for detecting a change in ice dynamics and predicting future ice sheet behaviour (Brunt et al., 2010; Bindschadler et al., 2011). Positioning of less than $100 \mathrm{~m}$ is required to give consistent results in modelling studies (Durand et al., 2009). Accuracies of 80-120 m are given for current mapping techniques (Rignot et al., 2011), but this is difficult to verify. In addition to mapping, a more detailed interpretation of the flexure pattern can yield insight into short-term ice dynamics and glacial and subglacial properties along this boundary (Walker et al., 2013).

Interferometric synthetic aperture radar (InSAR) uses the phase difference of electromagnetic waves to spatially map surface movement and is arguably the most precise satellite method to measure ice deformation (Goldstein et al., 1993; Joughin et al., 2010; Minchew et al., 2017). Differential InSAR (DInSAR) has been used to delineate the grounding line by identifying the transition from ice resting on land that is vertically stationary to ice shelves which move vertically due to tidal forcing (Rignot et al., 2011). Despite the very successful application of InSAR in grounding-line mapping, a number of limitations remain in the more detailed interpretation of the flexure pattern (Rabus and Lang, 2002; Han and Lee, 2014).

Firstly, phase differences are detected only in the radar look direction, meaning signals that originate from vertical displacement are mixed with those from horizontal ice flow and topography. Vertical displacement cannot be uniquely 
identified from a single interferogram. To overcome this problem, DInSAR is used to remove the observed phase difference caused by topography and continuous horizontal ice flow. Residual errors caused by insufficiently well known surface topography may alter the estimated flexure profile. The assumption that horizontal velocity remains constant between satellite passes may be incorrect as flexural bending effects may alter the flow field (Doake et al., 2002), and variations in subglacial water pressure can modify the ice flow up to tens of kilometres upstream of the ground line over tidal frequencies (Anandakrishnan et al., 2003; Gudmundsson, 2007; Marsh et al., 2013). These changes may not be linearly related to the tides (King et al., 2011; Rosier et al., 2015), further complicating the interpretation of interferograms.

Secondly, because two or more images are necessary for interferometry, the deformation pattern does not reveal the flexure at one snapshot in time but is a combination of processes over multiple tidal stages. Depending on bedrock slope and tidal forcing, the grounding-line position cannot be assumed to be fixed, and the resulting flexural profile may be shifted horizontally depending on the tidal stage. This grounding-line migration may be asymmetric (Tsai and Gudmundsson, 2015), and interferograms produced from combinations of negative and positive tides will not reflect a realistic tidal bending even under elastic conditions.

Although assumptions about horizontal velocity are not always correct, for approximate grounding-line positioning the vertical differential displacement is often much larger than the differential ice flow component over multi-day repeat times, which makes the grounding zone and the line of highest flexure clearly visible (Rack et al., 2000). Uncertainties in phase contributions from surface elevation have also been often neglected where the interferometric baseline is short, the grounding zone is sufficiently flat, or phase contributions of tidal displacement are particularly high. When compared to flexural models using tidal forcing from regional models like the the Circumpolar Antarctic Tidal Simulator (CATS) 2008, the dominant discrepancy to observations is often the uncertainty in tidal height due to atmospheric pressure and the related incomplete correction of the inverse barometric effect (Padman et al., 2003).

The observed shape of the tidal flexure profiles was found to be very similar to that of an elastic material in a number of grounding zones (Vaughan, 1995; Schmeltz et al., 2002; Marsh et al., 2014), although viscoelastic effects influence the bending process over tidal timescales (Reeh et al., 2000). Using a viscoelastic model for tidal flexure, Walker et al. (2013) showed that bedrock near the grounding line may act as a fulcrum and that leverage from the falling and rising ice shelf can cause a reversed vertical bending upstream of the grounding line. This may cause variations in the basal hydrology, which is a significant factor in ice stream dynamics and grounding-line migration (Sayag and Worster, 2011). Interferometry is currently well suited to map first-order dis- placements, but without more refined treatment of residual topography and varying horizontal flow it is difficult to detect the more subtle second-order processes such as the small upstream inverse bending predicted to occur at large tidal amplitudes.

In this study we selected an almost stagnant ice shelf for which a new high-resolution digital elevation model is available. In this way we minimize the complexity of ice sheet flow across the grounding zone so that we can better investigate the potential of high-accuracy DInSAR for flexural mapping. We evaluate a best-case scenario for the satellitebased measurement of tidal flexure in a grounding zone of the southern McMurdo Ice Shelf (SMIS) using ground validation measurements co-incident with satellite acquisitions. We focus in this study on the analysis of GPS and satellite data in combination with an analytical elastic bending model, but we draw on some other auxiliary information from tiltmeters, ice radar, and a tide model.

The paper is organized as follows: first we describe the measurement area, the field experiment, and the satellite data analysis. We then use the bending model to explain the observed GPS signals and show that interferometrically derived flexure curves contain recoverable information on bending stress and ice morphology in addition to vertical displacement. We discuss the results in the final section along with implications for the significantly improved observation of tidal flexure using SAR interferometry.

\section{Study area and GPS measurements}

The SMIS is an almost stagnant ice shelf located in an embayment to the northwest of the much faster flowing Ross Ice Shelf. Figure 1 shows the study region. The boundaries to the south are Minna Bluff (elevation: $1060 \mathrm{~m}$ ), to the north they are White Island $(760 \mathrm{~m})$ and Black Island $(1040 \mathrm{~m})$, and to the west they are Mt Discovery $(2690 \mathrm{~m}$ ) and Brown Island $(816 \mathrm{~m})$. The ice shelf connects to the northern McMurdo Ice Shelf between Brown and Black Island but is completely grounded above sea level at the saddle between Black and White Island. Edgar ice rise acts as a pinning point between the southern tip of Black Island and Minna Bluff. There is only very little ice discharge from the surrounding catchment basins, and the main inflow occurs in the northeast from White Island. The ice shelf is generally thicker in the north, where the snow accumulation is higher, and thins to the south and the west. This thinning can be seen in surface elevation gradients as freeboard gets lower from the north to the south. Basal freezing was detected in the southern and western areas near Minna Bluff; in these areas the surface mass balance is generally low or negative (Fitzsimons et al., 2012).

We conducted field measurements along a $4.5 \mathrm{~km}$ long profile across the grounding zone south of White Island and installed GPS and tiltmeter stations for a 2.5 -month period (9 November 2014 to 23 January 2015). We obtained con- 
Table 1. GPS positions with average ice shelf displacements over the fieldwork period and their estimated distance from the grounding line (GL) before and after application of strain correction (see text). The flow direction is measured in degrees from north.

\begin{tabular}{lcccr}
\hline$\# \#$ & Geog. position (S, E) & $\begin{array}{c}\text { Velocity } \\
\left(\mathrm{m} \mathrm{a}^{-1}\right)\end{array}$ & $\begin{array}{c}\text { Flow } \\
\text { direction }\end{array}$ & $\begin{array}{r}\text { Distance from } \\
\text { GL (m) }\end{array}$ \\
\hline GPS 2 & $-78^{\circ} 15^{\prime} 11^{\prime \prime}, 167^{\circ} 7^{\prime} 41^{\prime \prime}$ & 1.95 & 251.1 & $200 / 400$ \\
GPS 4 & $-78^{\circ} 15^{\prime} 43^{\prime \prime}, 167^{\circ} 7^{\prime} 30^{\prime \prime}$ & 3.41 & 265.1 & $1200 / 1400$ \\
GPS 6 & $-78^{\circ} 16^{\prime} 16^{\prime \prime}, 167^{\circ} 7^{\prime} 19^{\prime \prime}$ & 4.98 & 265.1 & $2200 / 2400$ \\
GPS 7 & $-78^{\circ} 17^{\prime} 22^{\prime \prime}, 167^{\circ} 6^{\prime} 53^{\prime \prime}$ & 7.25 & 283.4 & $4200 / 4400$ \\
\hline
\end{tabular}
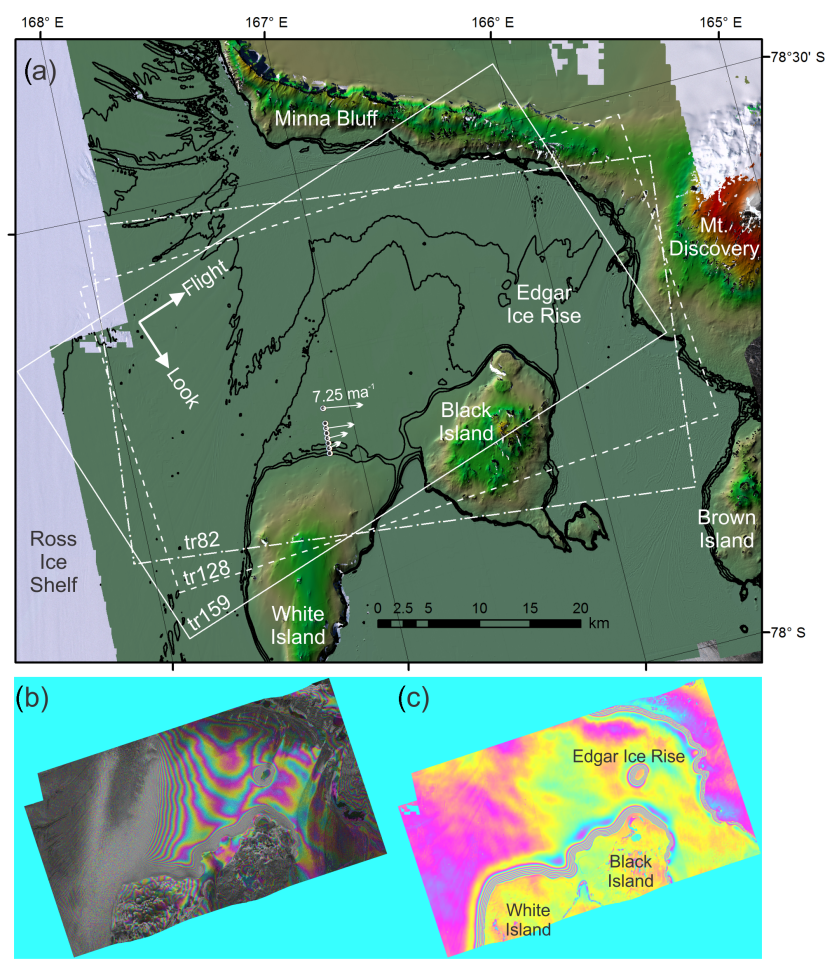

Figure 1. (a) Digital elevation model of the investigation area based on WorldView-1/2 stereo satellite imagery (October 2010November 2011) in the southern McMurdo Sound. TerraSAR-X image frames of three descending satellite tracks are shown. On the ice shelf a few contour lines at $10 \mathrm{~m}$ separation are plotted as well as average displacements vectors for the measurement profile south of White Island. One original and one fully processed interferogram (t128) are shown in (b) and (c), respectively (DInSAR combination 9, Table 3).

tinuous records of tidal bending and ice movement from tilt and position measurements coincident with SAR satellite acquisitions. A total of 7 measurement stations were equipped with differential GPS (station 2, 4, 6, and 7) and/or tiltmeters (station 1 to 6 ). For the study presented here we primarily make use of the data from the four GPS stations which operated over varying periods of time (Table 1). Every station included a barometer for measuring atmospheric pressure and a temperature sensor. Dual-frequency GPS data were recorded at $30 \mathrm{~s}$ intervals.

We processed the raw GPS data using Track v1.29 software (Herring et al., 2010). To obtain coordinate time series for each ice site, we processed them relative to a continuous GPS at Scott Base $47 \mathrm{~km}$ away (Blick, 2010), using precise GPS orbits provided by the International GNSS Service (Dow et al., 2009) and a satellite elevation cutoff angle of $10^{\circ}$. We estimated station positions and tropospheric zenith delays at every measurement epoch, constraining their time evolution to reduce noise but without damping signal $(5 \mathrm{~mm} / \mathrm{sqrt}(30 \mathrm{~s})$ and $0.1 \mathrm{~mm} / \mathrm{sqrt}(30 \mathrm{~s})$, respectively). We applied models of antenna phase centre variations (IGS08_1884.atx) and solid-earth tides. Differences in ocean tide loading over $<50 \mathrm{~km}$ are negligible in this region. To correct for variations in atmospheric pressure, we apply a conventional inverse barometer correction of $-1 \mathrm{~cm} \mathrm{hPa}^{-1}$ (Padman et al., 2003) with pressure taken as anomalies to the long-term mean obtained from our measured surface pressures at each site. Analysis of GPS time series after de-tiding and removing the inverse barometer effect suggests the GPS positions have a precision of $\sim 0.5-1 \mathrm{~cm}$ in the horizontal and $\sim 1-2 \mathrm{~cm}$ in the vertical.

To obtain de-tided data, we solved for all tidal constituents which satisfied the Rayleigh criterion of 2 (Godin, 1972; Codiga, 2011). For time series with durations less than 182 days we separated constituents with similar frequencies (K2/S2, P1/K1, O1/K1) using a standard inference approach based on amplitude and phase relationships derived from the Scott Base tide gauge $\sim 50 \mathrm{~km}$ away. We used the derived tidal constituents to predict the tidal elevation at times outside the GPS observation periods.

Ice thickness of approximately $250 \mathrm{~m}$ was also measured along the profile using a $25 \mathrm{MHz}$ ground-penetrating radar system (Wild et al., 2017).

\section{Satellite data acquisition}

For this study a total of 12 TerraSAR-X scenes were acquired between 25 October and 2 December 2014. These images are in right-looking StripMap mode on descending satellite tracks (track 82, 128, and 159; Fig. 1 and Table 2). On every satellite track the separation of image acquisitions (repeat 
pass) is 11 days. Image pairs show a high phase coherence allowing the formation of nine differential interferograms from six image triplets and three other InSAR combinations (Table 3). At our field site the radar look direction (radar range) is aligned with the direction of the field measurement profile across the grounding zone. The satellite heading (flight or azimuth direction) is orientated along the grounding line at the field site and is almost exactly parallel to the grounding line for track 82 . The radar incidence angle is close to $45^{\circ}$ so that all interferograms are almost equally sensitive in detecting vertical displacements and horizontal motion. The sunsynchronous satellite orbit and diurnal tidal regime in this area mean that during the observation period the image acquisitions always occurred close to the high tide, albeit with variation in amplitude depending on the spring-neap tidal cycle.

Most of our interferograms have a differential perpendicular baseline of tens to hundreds of metres and only one baseline is close to zero (Table 3). If uncorrected, these baselines introduce significant topographic phase contributions even in the relatively flat grounding zones. In order to reliably detect displacements with sub-centimetre accuracy, a new highresolution digital elevation model (DEM) based on WorldView stereo imagery with posted accuracy of $2 \mathrm{~m}$ was used to simulate the topographic phase (Fig. 1). An example of a "flat" differential interferogram (without topographic effects) containing primarily residual tidal fringes in the grounding zone is shown in Fig. 1c. The single-look slant-range complex (SSC) data were first multi-looked in range and azimuth to an interferogram pixel spacing of slightly below $10 \times 10 \mathrm{~m}$, and adaptive fringe filtering was applied. It was found that this filtering adequately reduced the phase noise in our analysis. Interferometric products were orthorectified to polar stereographic projection using the WorldView DEM at $10 \mathrm{~m}$ pixel spacing. A $50 \mathrm{~m}$ running mean was then applied to the resulting flexure profiles.

\section{GPS and satellite data analysis}

In this study we focus on the interpretation of the GPS measurements as a detailed analysis of the tiltmeter data, and temporal variation in bending is presented and used elsewhere (Wild et al., 2017). However, it is important to note that tiltmeter measurements at station 1 (where no GPS was installed) strongly indicate that this position is grounded with a very small but still detectable bending similar to other upstream grounding-line locations in Antarctica (Smith, 1991). All four GPS stations in this study were installed on floating ice and, as expected, show increasing vertical amplitudes with distance from the grounding line (Fig. 2). The mean horizontal flow velocity in this area is less than $7.3 \mathrm{ma}^{-1}$ (Fig. 1). GPS 7 was located in an area assumed to be freely floating but this GPS stopped recording after about 11 days. The overlap in time with GPS 6 allows us to conclude that the
Table 2. Satellite track number and acquisition times as well as scene centre heading (degrees from north) and radar incidence angles of TerraSAR-X images acquired over the study period in 2014.

\begin{tabular}{|c|c|c|c|}
\hline Track & Date, time (UTC) & Heading & Incidence \\
\hline 82 & $\begin{array}{l}25 \text { Oct, } 12: 32 \\
5 \text { Nov, } 12: 32 \\
16 \text { Nov, } 12: 32 \\
27 \text { Nov, } 12: 32\end{array}$ & 275.4 & 44.5 \\
\hline 128 & $\begin{array}{l}28 \text { Oct, } 13: 14 \\
8 \text { Nov, 13:14 } \\
19 \text { Nov, 13:14 } \\
30 \text { Nov, 13:14 }\end{array}$ & 265.0 & 44.6 \\
\hline 159 & $\begin{array}{l}30 \text { Oct, } 14: 14 \\
10 \text { Nov, } 14: 14 \\
21 \text { Nov, } 14: 14 \\
2 \text { Dec, } 14: 14\end{array}$ & 250.1 & 39.3 \\
\hline
\end{tabular}

timing of the tidal displacement at GPS 7 is in phase with and of a very similar amplitude to that of GPS 6 (which is therefore also very close to freely floating). This is supported by nine differential interferograms, which reveal a mean height difference between position 6 and 7 of $0.000 \pm 0.016 \mathrm{~m}$ (Table 3).

In addition to the strong vertical tidal signal there is also a clear horizontal tide-synchronous displacement that is detected by all GPS stations. In contrast to the vertical motion, which decreases towards the grounding line, the horizontal amplitudes increase towards the grounding line and are largest at GPS 2 with a magnitude about $60 \%$ of the vertical amplitude (Fig. 2). This horizontal tidal signal is predominantly perpendicular to the grounding line (along the measurement profile). This signal fades quickly with distance from the grounding line, and the ratio between vertical and horizontal amplitude decreases to 8, 2, and $1 \%$ at GPS 4, 6 , and 7, respectively (shown as symbols in Fig. 4c). While GPS 7 is $4500 \mathrm{~m}$ away from station 1, the horizontal signal is still significant and detectable over the 11-day period (Fig. 2d).

The acquired sequence of satellite scenes allows us to derive a total of nine different combinations of differential tidal bending curves (shown in Fig. 5a). Validation of the differential height from interferometry by two GPS stations is possible for DInSAR combination 6 (Table 3), which reveals a difference between the two independent methods of $h_{\mathrm{GPS} 2}-h_{\mathrm{DInSAR}}=-0.012 \mathrm{~m}$ and $h_{\mathrm{GPS} 6}-h_{\mathrm{DInSAR}}=0.004 \mathrm{~m}$. Although GPS 6 is relatively close to the grounding line, it happens to be close to the inflection point of surface slope (Bindschadler et al., 2011), in a position where the surface elevation changes are similar to that of the freely floating ice shelf. We have expanded our GPS time series by adjusting the CATS2008 tide model with data from GPS 6. Taking into account the inverse barometric 

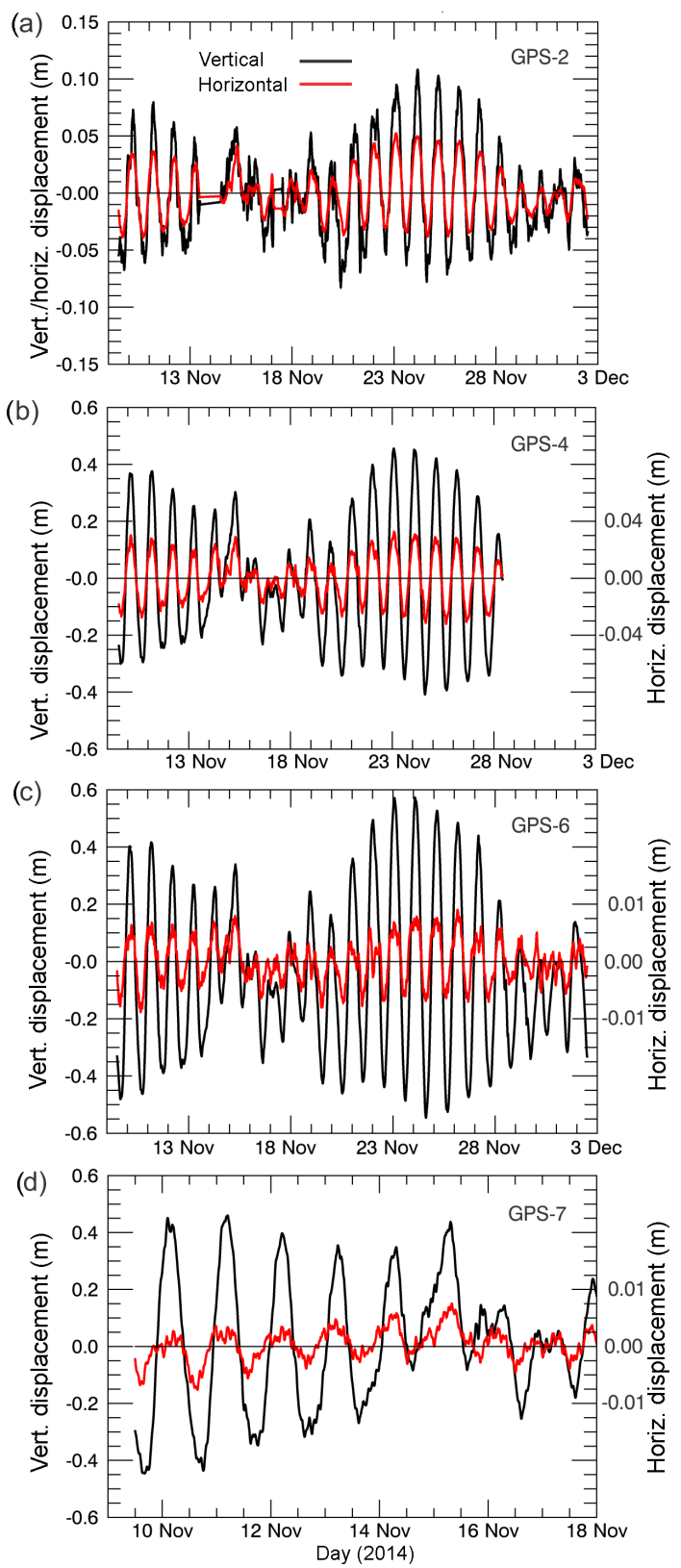

Figure 2. Vertical (black) and horizontal (red) displacements at four GPS stations between 9 November and 2 December 2014. The horizontal displacement is the component perpendicular to the grounding line with positive values for movements towards White Island (about north).

effect, the mean difference between this tide model and interferometry in the area which is assumed to be freely floating is $-0.002 \pm 0.086 \mathrm{~m}$ (Table 3 ). The high standard deviation suggests that the complexity of the tides under the ice shelf is incompletely captured by the tide model.

At radar incidence angles close to $45^{\circ}$ (Table 2) the interferometric sensitivity to horizontal and vertical displacements is similar. From the GPS analysis it is clear that the

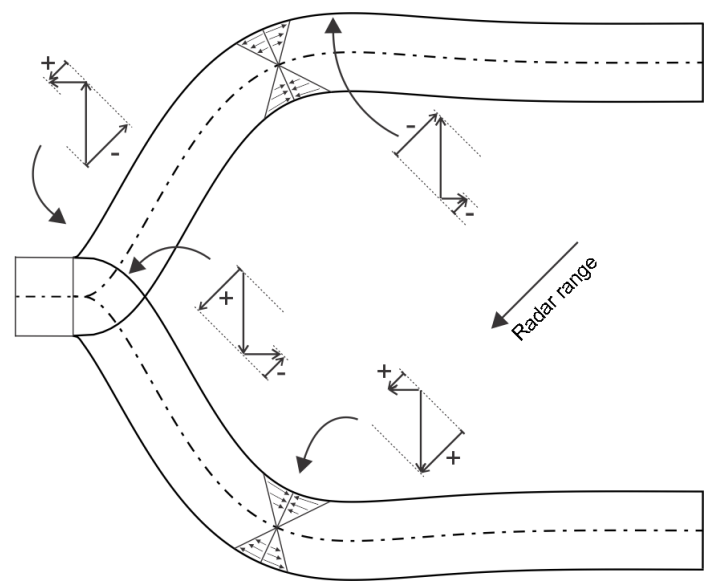

Figure 3. Schematic of grounding zone ice shelf flexure, bending stresses, and associated surface displacement components in radar range at low and high tide. Surface extension (convex surface shape) causes a horizontal displacement component towards the sensor ("-" for radar range shortening) and vice versa ("+" for radar range lengthening). The neutral layer located in the middle of the beam experiences only vertical displacement.

horizontal velocity fluctuations are correlated with the vertical tidal displacements and that these components likely do not cancel out in the DInSAR analysis. The differential horizontal velocity components therefore potentially distort the interferometrically derived flexure curves. This is especially problematic near the grounding line, where horizontal and vertical displacement components are of the same order of magnitude. As the horizontal velocity fluctuations appear to be synchronous to the vertical tidal displacements, the question arises about the nature of these fluctuations and how they should be managed.

\section{Analysis of bending stress and correct interpretation of flexure curves}

Figure 3 shows a schematic of ice shelf bending in the grounding zone illustrating bending stresses at increasing distance from the neutral layer in the beam centre. In our consideration the beam is clamped on the left (displacement and slope are zero at $x=0$ ) and freely moving with the tidal wave on the right end. According to a model of elastic ice shelf flexure, the bending of the neutral layer can then be described by (Smith, 1991)

$w(x)=A(t)\left(-1+e^{-\beta x}(\cos \beta x+\sin \beta x)\right)$,

with the spatial wave number given by

$\beta^{4}=\frac{3 \rho_{\mathrm{w}} g\left(1-v^{2}\right)}{E H^{3}}$.

In Eq. (2) $\rho_{\mathrm{w}}$ is the density of sea water $\left(1027.7 \mathrm{~kg} \mathrm{~m}^{-3}\right)$, $g$ is the gravitational constant $\left(9.81 \mathrm{~m} \mathrm{~s}^{-2}\right), v$ is the Poisson 
(a)

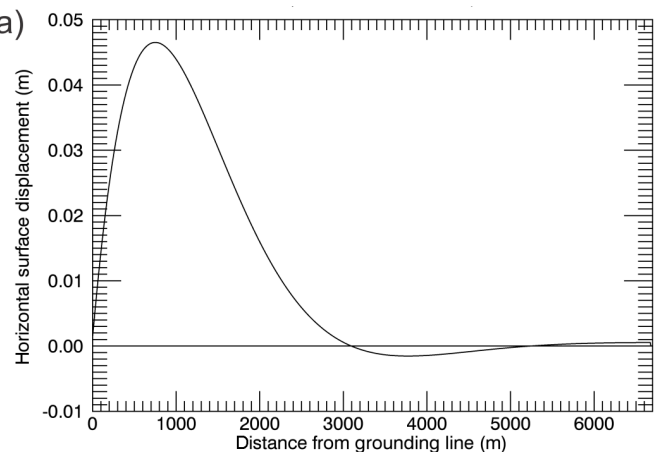

(b)

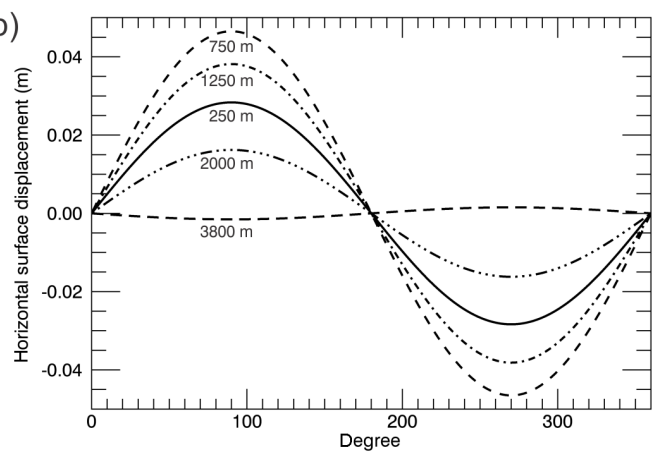

(c)

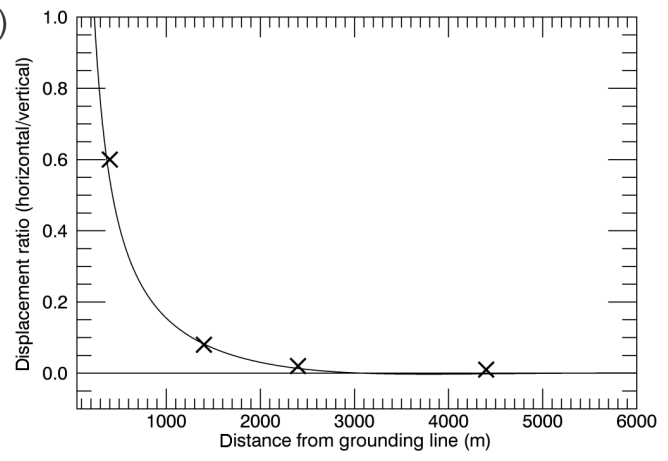

Figure 4. Elastic model calculations for an ice shelf with $250 \mathrm{~m}$ thickness and $E=1.5 \mathrm{GPa}$ for horizontal surface displacement integrated from surface strain perpendicular to the grounding line (a) for a typical high tide in our study area $(0.55 \mathrm{~m})$ and (b) over a tidal cycle at five different distances from the grounding line. The mean ratio between the horizontal and vertical displacement is shown in (c) together with the values measured at the four GPS stations ( $x$ symbols).

ratio (0.31), $H$ is the ice shelf thickness, and $E$ is the elastic Young modulus of ice (see discussion below for values of $H$ and $E$ ).

For pure bending, the curvature $\kappa(x)$ of the neutral surface at some distance $x$ from the grounding line is given by (Beer et al., 2012)

$\kappa(x)=\frac{1}{r(x)}=-\frac{w^{\prime \prime}(x)}{\left(1+w^{\prime 2}\right)^{3 / 2}}$,

where $r$ is the radius of curvature of the neutral surface, and $w^{\prime}$ and $w^{\prime \prime}$ are the first and second derivative of Eq. (1), re-

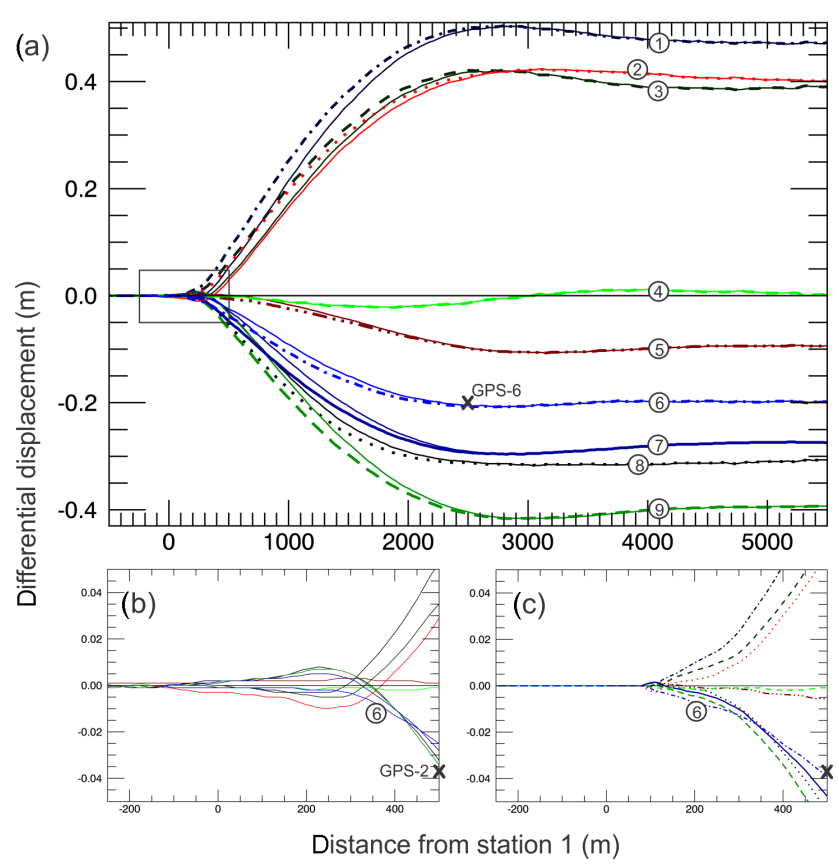

Figure 5. (a) Tidal flexure along the validation profile for nine different combinations of interferograms without surface strain correction (thinner full lines) and with elastic strain correction applied (dashed lines). The close-up shows the area near the grounding line for (b) the uncorrected and (c) the corrected displacement. The numbers in (a) refer to the differential interferograms in Table 1. Symbols $(x)$ show the GPS validation measurements for profile 6 .

spectively. The length of every fraction $\Delta x$ of the neutral surface remains constant during bending by the arc $\Delta \alpha=\kappa \Delta x$, but at some distance $z$ normal to the neutral layer the new surface length is

$\Delta x+\delta x=(r(x)+z) \Delta \alpha$

e.g., at high tide the stress and strain are negative near the grounding line in the upper portion of the ice shelf (compression) and positive in the lower portion (tension). Integration of the surface strain along a model beam with $6500 \mathrm{~m}$ length, $H=250 \mathrm{~m}$, and a positive tidal displacement, $A=0.55 \mathrm{~m}$, yields an expected surface displacement as shown in Fig. $4 \mathrm{a}$ with a maximum about $750 \mathrm{~m}$ from the grounding line. After reaching zero at about $3000 \mathrm{~m}$, the displacement changes sign for the next $2000 \mathrm{~m}$. With increasing distance from the grounding line the displacement approaches zero. Figure $4 \mathrm{~b}$ shows the expected horizontal surface movement during a typical tidal cycle with $A(t)= \pm 0.55 \mathrm{~m}$ at different distances to the grounding line. In Fig. $4 \mathrm{c}$ the ratio between horizontal and vertical displacement is shown together with the values measured at the GPS stations; for this figure the grounding line is fixed $100 \mathrm{~m}$ downstream of station 1 , which is discussed further below.

With this in mind it is possible to improve the interpretation of the interferograms. We use the area $500 \mathrm{~m}$ upstream 
Table 3. Acquisition dates and spatial perpendicular baselines (___ ) of differential interferograms listed with displacements (in m) at the freely floating ice shelf (position GPS 6 and 7) compared to the adjusted CATS tide model. For DInSAR combination 6 the corresponding value measured by GPS 6 is also shown.

\begin{tabular}{llrrrr}
\hline $\begin{array}{l}\text { DInSAR } \\
\text { number }\end{array}$ & Time intervals & $\begin{array}{r}-_{-} \\
(\mathrm{m})\end{array}$ & $\begin{array}{r}\text { DInSAR at } \\
\text { GPS 6/GPS } 8\end{array}$ & GPS 6 & Model \\
\hline 1 & 30 Oct-10 Nov, 21 Nov-2 Dec & -75 & $0.496 / 0.476$ & - & 0.437 \\
2 & 5-16 Nov, 16-27 Nov & -190 & $0.407 / 0.410$ & - & 0.477 \\
3 & 28 Oct-8 Nov, 19-30 Nov & -70 & $0.417 / 0.388$ & - & 0.437 \\
4 & 8-19 Nov, 19-30 Nov & -220 & $-0.014 / 0.009$ & - & 0.077 \\
5 & 25 Oct-5 Nov, 5-16 Nov & 187 & $-0.097 /-0.097$ & - & -0.179 \\
6 & 10-21 Nov, 21 Nov-2 Dec & 28 & $-0.205 /-0.197$ & -0.201 & -0.082 \\
7 & 30 Oct-10 Nov, 10-21 Nov & 50 & $-0.291 /-0.279$ & - & -0.355 \\
8 & 25 Oct-5 Nov, 16-27 Nov & 5 & $-0.310 /-0.314$ & - & -0.298 \\
9 & 28 Oct-8 Nov, 8-19 Nov & 290 & $-0.404 /-0.398$ & - & -0.514 \\
\hline
\end{tabular}

of station 1 as the reference area for zero deflection in the unwrapped interferograms (Fig. 5a). This is justified by the fact that beyond about $200 \mathrm{~m}$ upstream of station 1 the slopes of all flexure curves are very close to zero. This simultaneously confirms that the DEM is of a high enough quality to completely remove the topographic phase. Prior to applying the model correction, we identify a local maximum for all flexure curves about $200 \mathrm{~m}$ downstream of station 1, possibly indicating a fulcrum and reversed upstream bending. At tides higher than $|0.25| \mathrm{m}$ these values are up to $2 \%$ of the differential tidal displacement on the freely floating ice shelf but of the opposite sign (Fig. 5b). We now use the analytical elastic model from before but forced with the satellite-observed tidal amplitude in the area of station 7 and with $H=250 \mathrm{~m}$ and $E=1.5 \mathrm{GPa}$ to apply the correction terms for horizontal movement. We do this by taking into account the radar imaging geometries (satellite heading and radar viewing angles in Table 2). This approach is supported by Fig. 4c, where the GPS measurements align well with the ratio curve by fixing the grounding-line location at a point $100 \mathrm{~m}$ downstream of station 1 . The new bending curves are steeper in the first $750 \mathrm{~m}$ downstream of the grounding line and shallower between 750 and $2500 \mathrm{~m}$. As the model is forced by the interferometric displacement in the freely floating area, the corrected curves increasingly converge with the uncorrected solutions further downstream. By positioning the model grounding line $100 \mathrm{~m}$ downstream of station 1, the local maxima described above are removed, cross-overs of the resulting corrected flexure curves are largely avoided, and apparent groundingline migration is minimized. We therefore conclude that the true grounding-line position must be very close to the one shown in Fig. 5c.

\section{Discussion}

The initial interferometrically observed bending pattern in Fig. $5 \mathrm{~b}$ suggests the existence of a grounding-line fulcrum around $300 \mathrm{~m}$ downstream of station 1 . The apparent reversed bending upstream of this point with a magnitude of about $2 \%$ of the tidal amplitude however contradicts tiltmeter observations (Wild et al., 2017) which show that changes in surface slope at station 1 are synchronous and in phase with station 2. Furthermore, the tide-synchronous horizontal velocity components occurring perpendicular to the grounding line show a maximum at station 2 . These two observations make it clear that the apparent vertical movement is actually horizontal surface strain as a result of the bending stress and that the related horizontal velocity components need to be separated from the vertical displacement in order to obtain a more realistic satellite-derived flexure profile.

We used an elastic bending model with simple assumptions of an ice shelf of uniform thickness and density to account for these effects in the interferograms. With this adjustment, the apparent upstream bending disappears and the grounding line, which was estimated to be about $300 \mathrm{~m}$ downstream of station 1 , shifts about $200 \mathrm{~m}$ (or one ice thickness) upstream (Fig. 5c). The biggest changes in the slope of the bending curves are found just downstream of the grounding line where the curvature of the ice flexure is greatest. The original flexure curves were more distorted near the grounding line. As convex and concave bending cancel each other out from the grounded to the freely floating area, the full interferometric tidal amplitude on the ice shelf is identical in the corrected and uncorrected case. The accuracy of the obtained flexure curves in our study area is high, partly because the chosen sites experience hardly any ice flow, and also because of a presumably steep bed topography resulting in a small grounding-line migration over the tidal cycle. This high accuracy is supported by improved agreement between interferometry and GPS measurement. As an example the vertical displacement at GPS 2 about $400 \mathrm{~m}$ downstream of the newly estimated grounding-line position is $-0.037 \mathrm{~m}$ for the acquisitions dates of DInSAR combination 6. This now compares well to $-0.039 \mathrm{~m}$ of the corrected DInSAR measurement (Fig. 6c). 
An important and possibly flawed assumption in our analysis is the elasticity of ice. This is normally quietly assumed in the DInSAR derivation of the flexural profiles, as only elastic materials will allow the linear superposition of individual profiles to result in another flexure profile equivalent to a differential tidal forcing. It is also important to note that all the satellite images have been acquired at high tide and that negative differential tides in Fig. 5 are only a consequence of the negative differences between differential positive tides. However, the synchrony of the vertical and horizontal displacement components suggests that on the short tidal timescales the bending response is dominated by elastic behaviour. In our analysis we also assume that the ice shelf is of uniform thickness and density. The variation of density and temperature with depth, basal crevasses, and groundingline migration can altogether change the shape of the flexure profile, as the neutral bending layer is likely not in the centre of the ice shelf column (Jenkins et al., 2006; Rosier et al., 2017).

Despite all these simplifications the good agreement between GPS measurements, the modelled bending signal, and the corrected flexure profiles indicate that we capture the first-order effects of bending stresses. This is especially supported by the clear result of grounding-line location and the simplified bending patterns close to the grounding line. The interferometric measurement clearly captures the surface strain pattern as a result of the bending of a beam with finite thickness. This additional adjustment must be considered at all sites if interferometrically derived flexure curves are used to pinpoint the grounding-line location where the radar look direction is significantly misaligned with the grounding line. Ice thickness and tidal amplitude in our study area are relatively small. In many other regions, for example at the Ronne-Filchner Ice Shelf, bending effects are expected to be more significant. For an ice shelf with $1000 \mathrm{~m}$ thickness and $1 \mathrm{~m}$ tidal amplitude we estimate $0.12 \mathrm{~m}$ horizontal surface displacement at $2130 \mathrm{~m}$ distance from the grounding line. If interpreted as vertical displacement, it would significantly change the shape of the tidal flexure curve in a typical DInSAR imaging geometry. Furthermore, GPS observations of horizontal modulation of flow near grounding lines (e.g. Marsh et al., 2013) should be corrected for this effect before their application to study other grounding-line effects.

\section{Conclusion}

We examined tidal motion of ice in an ice shelf grounding zone using a combination of satellite interferometry, GPS, and modelling. Our study region in the McMurdo Ice Shelf grounding zone is unusual compared to previously studied regions, as the ice flow across the grounding line is almost zero. As such, the motion is effectively free from basal dynamics, allowing us to separate out elastic bending processes and correct interferograms for this effect to obtain an accurate grounding-line location.

From the implicit elastic assumption commonly made in DInSAR analysis it follows that different flexure profiles can be superimposed to yield another flexure profile at the differential tide. This is certainly not true for a viscoelastic material such as ice; as we discovered signs of viscoelasticity in at least two flexure profiles, this needs further investigation. However, assuming simple elastic ice properties, we find that the adjusted ice shelf flexure profiles better fit modelled bending profiles to estimate material properties such as Young's modulus of ice. We have chosen our field area because of the very simple boundary conditions, which are a straight grounding line with very little ice flow. Our findings should be able to be extended to other more complex grounding zone situations.

Interferograms of tidal flexure zones contain precise information on bending stresses which depend on ice thickness and tidal forcing. This information can be revealed in the grounding zone if a precise elevation model is available to subtract the topographic phase. By separating non-linear horizontal movement from vertical displacement using simple assumptions of tidal elastic tidal bending around a neutral layer, we obtain more realistic ice shelf flexure profiles in this glaciologically important region. With this correction, we can more accurately determine the position of the grounding line in our study area using differential interferometry, eliminating an erroneous signal otherwise misinterpreted as grounding-line migration or reversed tidal bending upstream of the grounding line.

Data availability. Data acquired for this study are available upon request from the first author.

Competing interests. The authors declare that they have no conflict of interest.

Acknowledgements. This study is a result of NZARI project 20145. Matt A. King is a recipient of an Australian Research Council Future Fellowship (project number FT110100207). This research was supported under the Australian Research Council's Special Research Initiative for Antarctic Gateway Partnership (project ID SR140300001). We greatly acknowledge the support of fieldwork by M. Ryan and D. Price, and the design of GPS/tiltmeter stations by G. Graham, N. Key, and J. Harrison (all University of Canterbury). We also acknowledge the logistics support by Antarctica New Zealand, especially for the removal of GPS stations in January 2015. We used Gamma Remote Sensing AG interferometric processing software in this study; Trimble Navigation NZ Ltd. supplied GPS receivers for fieldwork. Satellite data acquisition and provision were accomplished through the German Aerospace Agency (DLR) through project HYD1421. Land Information New Zealand freely provided the Scott Base GPS data. This material 
is based on data services provided by the UNAVCO Facility with support from the National Science Foundation (NSF) and National Aeronautics and Space Administration (NASA) under NSF Cooperative Agreement no. EAR-0735156. WorldView DEM tiles were provided through the Polar Geospatial Center (P. Morin, University of Minnesota).

Edited by: Kenny Matsuoka

Reviewed by: Bernhard Rabus and Ryan Walker

\section{References}

Anandakrishnan, S., Voigt, D. E., Alley, R. B., and King, M. A.: Ice stream D flow speed is strongly modulated by the tide beneath the Ross Ice Shelf, Geophys. Res. Lett., 30, 1361, https://doi.org/10.1029/2002g1016329, 2003.

Beer, F. B., Johnston, E. R., Dewolf, J. T., and Mazurek, D. F.: Mechanics of Materials, 6th Edn., McGraw Hill, New York, 2012.

Bindschadler, R., Choi, H., Wichlacz, A., Bingham, R., Bohlander, J., Brunt, K., Corr, H., Drews, R., Fricker, H., Hall, M., Hindmarsh, R., Kohler, J., Padman, L., Rack, W., Rotschky, G., Urbini, S., Vornberger, P., and Young, N.: Getting around Antarctica: new high-resolution mappings of the grounded and freely-floating boundaries of the Antarctic ice sheet created for the International Polar Year, The Cryosphere, 5, 569-588, https://doi.org/10.5194/tc-5-569-2011, 2011.

Blick, G.: Antarctica-POLENET GPS Network: SCTBScott Base GPS P.S., UNAVCO, GPS Data Set, https://doi.org/10.7283/T5CF9N6P, 2010.

Brunt, K. M., Fricker, H. A., Padman, L., Scambos, T. A., and O'Neel, S.: Mapping the grounding zone of the Ross Ice Shelf, Antarctica, using ICESat laser altimetry, Ann. Glaciol., 51, 7179, https://doi.org/10.3189/172756410791392790, 2010.

Codiga, D. L.: Unified Tidal Analysis and Prediction Using the UTide Matlab Functions, Technical Report 2011-01, Graduate School of Oceanography, University of Rhode Island, Narragansett, RI, 59 pp., 2011.

Doake, C. S. M., Corr, H. F. J., Nicholls, K. W., Gaffikin, A., Jenkins, A., Bertiger, W. I., and King, M. A.: Tide-induced lateral movement of Brunt Ice Shelf, Antarctica, Geophys. Res. Lett., 29, 1226, https://doi.org/10.1029/2001GL014606, 2002.

Dow, J. M., Neilan, R. E., and Rizos, C.: The International GNSS Service in a changing landscape of Global Navigation Satellite Systems, J. Geodesy, 83, 191-198, https://doi.org/10.1007/s00190-008-300-3, 2009.

Durand, G., Gagliardini, O., de Fleurian, B., Zwinger, T., and Le Meur, E.: Marine ice sheet dynamics: Hysteresis and neutral equilibrium, J. Geophys. Res.-Earth, 114, F03009, https://doi.org/10.1029/2008jf001170, 2009.

Fitzsimons, S., Mager, S., Frew, R., Clifford, A., and Wilson, G.: Formation of ice-shelf moraines by accretion of sea water and marine sediment at the southern margin of the McMurdo Ice Shelf, Antarctica, Ann. Glaciol., 53, 211-220, https://doi.org/10.3189/2012AoG60A155, 2012.

Godin, G.: The analysis of tides, University of Toronto Press, Toronto, 1972.

Goldstein, R. M., Engelhardt, H., Kamb, B., and Frolich, R. M.: Satellite Radar Interferometry for Monitoring Ice-Sheet Motion
- Application to an Antarctic Ice Stream, Science, 262, 15251530, https://doi.org/10.1126/science.262.5139.1525, 1993.

Gudmundsson, G. H.: Tides and the flow of Rutford ice stream, West Antarctica, J. Geophys. Res.-Earth, 112, F04007, https://doi.org/10.1029/2006jf000731, 2007.

Han, H. and Lee, H.: Tide deflection of Campbell Glacier Tongue, Antarctica, analyzed by double-differential SAR interferometry and finite element method, Remote Sens. Environ., 141, 201213, https://doi.org/10.1016/j.rse.2013.11.002, 2014.

Herring, T. A., King, R. W., and McCluky, S. C.: Documentation for the GAMIT GPS analysis software 10.40, Massachusetts Institute of Technology, Massachusetts, 2010.

Jenkins, A., Corr, H. F. J, Nicholls, K. W., Stewart, C. L., and Doake, C. S. M.: Interactions between ice and ocean observed with phase-sensitive radar near an Antarctic ice-shelf grounding line, J. Glaciol., 52, 325-346, https://doi.org/10.3189/172756506781828502, 2006.

Joughin, I., Smith, B. E., and Abdalati, W.: Glaciological advances made with interferometric synthetic aperture radar, J. Glaciol., 60, 526-536, https://doi.org/10.3189/002214311796406158, 2010.

King, M. A., Makinson, K., and Gudmundsson, G. H.: Nonlinear interaction between ocean tides and the Larsen $\mathrm{C}$ Ice Shelf system, Geophys. Res. Lett., 38, L08501, https://doi.org/10.1029/2011gl046680, 2011.

Marsh, O. J., Rack, W., Floricioiu, D., Golledge, N. R., and Lawson, W.: Tidally induced velocity variations of the Beardmore Glacier, Antarctica, and their representation in satellite measurements of ice velocity, The Cryosphere, 7, 1375-1384, https://doi.org/10.5194/tc-7-1375-2013, 2013.

Marsh, O. J., Rack, W., Golledge, N. R., Lawson, W., and Floricioiu, D.: Grounding-zone ice thickness from InSAR: inverse modelling of tidal elastic bending, J. Glaciol., 60, 526-536, https://doi.org/10.3189/2014JoG13J033, 2014.

Minchew, B. M., Simons, M., Riel, B., and Milillo, P.: Tidally induced variations in vertical and horizontal motion on Rutford Ice Stream, West Antarctica, inferred from remotely sensed observations, J. Geophys. Res.-Earth, 122, 167-190, https://doi.org/10.1002/2016JF003971, 2017.

Padman, L., King, M., Goring, D., Corr, H., and Coleman, R.: Ice-shelf elevation changes due to atmospheric pressure variations, J. Glaciol., 49, 521-526, https://doi.org/10.3189/172756503781830386, 2003.

Rabus, B. T. and Lang, O.: On the representation of ice-shelf grounding zones in SAR interferograms, J. Glaciol., 48, 345356, https://doi.org/10.3189/172756502781831197, 2002.

Rack, W., Doake, C. S. M., Rott, H., Siegel, A., and Skvarca, P.: Interferometric analysis of the deformation pattern of the northern Larsen Ice Shelf, Antarctic Peninsula, compared to field measurements and numerical modeling, Ann. Glaciol., 31, 205-210, https://doi.org/10.3189/172756400781819851, 2000.

Reeh, N., Mayer, C., Olesen, O. B., Christensen, E. L., and Thomsen, H. H.: Tidal movement of Nioghalvfjerdsfjorden glacier, northeast Greenland: observations and modelling, Ann. Glaciol., 31, 111-117, https://doi.org/10.3189/172756400781820408, 2000.

Rignot, E., Mouginot, J., and Scheuchl, B.: Antarctic grounding line mapping from differential satellite 
radar interferometry, Geophys. Res. Lett., 38, L10504, https://doi.org/10.1029/2011gl047109, 2011.

Rosier, S. H. R., Gudmundsson, G. H., and Green, J. A. M.: Temporal variations in the flow of a large Antarctic ice stream controlled by tidally induced changes in the subglacial water system, The Cryosphere, 9, 1649-1661, https://doi.org/10.5194/tc9-1649-2015, 2015.

Rosier, S. H. R., Marsh, O. J., Rack, W., Gudmundsson, G. H., Wild, C. T., and Ryan, M.: On the interpretation of ice-shelf flexure measurements, J. Glaciol., 63, 783-791, https://doi.org/10.1017/jog.2017.44, 2017.

Sayag, R. and Worster, M. G.: Elastic response of a grounded ice sheet coupled to a floating ice shelf, Phys. Rev. E, 84, 036111, https://doi.org/10.1103/PhysRevE.84.036111, 2011.

Schmeltz, M., Rignot, E., and MacAyeal, D.: Tidal flexure along ice-sheet margins: comparison of InSAR with an elastic-plate model, Ann. Glaciol., 34, 202-208, https://doi.org/10.3189/172756402781818049, 2002.

Schoof, C.: Ice sheet grounding line dynamics: Steady states, stability, and hysteresis, J. Geophys. Res.-Earth, 112, F03S028, https://doi.org/10.1029/2006JF000664, 2007.
Smith, A. M.: The Use of Tiltmeters to Study the Dynamics of Antarctic Ice-Shelf Grounding Lines, J. Glaciol., 37, 51-58, https://doi.org/10.1017/S022143000042799, 1991.

Tsai, V. C. and Gudmundsson, G. H.: An improved model for tidally modulated grounding-line migration, J. Glaciol., 61, 216-222, https://doi.org/10.3189/2015JoG14J152, 2015.

Vaughan, D. G.: Tidal Flexure at Ice Shell Margins, J. Geophys. Res.-Sol. Ea., 100, 6213-6224, https://doi.org/10.1029/94jb02467, 1995.

Walker, R. T., Parizek, B. R., Alley, R. B., Anandakrishnan, S., Riverman, K. L., and Christianson, K.: Ice-shelf tidal flexure and subglacial pressure variations, Earth Planet. Sc. Lett., 361, 422428, https://doi.org/10.1016/j.epsl.2012.11.008, 2013.

Wild, C. T., Marsh, O. J., and Rack, W.: Viscosity and elasticity: a model intercomparison of ice-shelf bending in an Antarctic grounding zone, J. Glaciol., 63, 573-580, https://doi.org/10.1017/jog.2017.15, 2017. 